\title{
Design and Control of Autonomous Surface Vehicle to Support Bathymetry Survey in the Coastal Environment
}

\author{
Ahmad Fauzan Zakki ${ }^{*}$, , Aris Triwiyatno², Bandi Sasmito ${ }^{3}$, Krismon Budiono $^{2}$ \\ ${ }^{1}$ Naval Architecture Department, Engineering Faculty, Diponegoro University, 50275, Indonesia \\ ${ }^{2}$ Electrical Engineering Department, Engineering Faculty, Diponegoro University, 50275, Indonesia \\ ${ }^{3}$ Geodetical Engineering Department, Engineering Faculty, Diponegoro University, 50275, Indonesia
}

A R T I C L E I N F O

Article history:

Received: 16 July, 2019

Accepted: 16 August, 2019

Online: 21 August, 2019

Keywords:

Small Water-plane Area Twin

Hull

Autonomous Surface Vehicle

Bathymetry Survey

\begin{abstract}
A B S T R A C T
Traditionally bathymetry survey is generally carried out using boat, research vessel, and small craft which is equipped with the echo sounding instrument and involves many persons as the vessel crew. The survey method demands an additional cost because of the extra man power and an expensive vessel operational cost. An autonomous surface vehicle (ASV) which is equipped with echo sounder was developed by adopting small water-plane area twin hull (SWATH) hull form to support bathymetry survey in the coastal environment. The paper is focused on the design of hull and control system of the SWATH-ASV, electronic device and sensor selection for control of the vehicle. The hull and control system is designed to organize the surface vehicle to perform the defined mission from ground control station. The hull form geometry, hardware and software of the SWATH-ASV and the control system are presented.
\end{abstract}

\section{Introduction}

Recently, the development of unmanned surface vehicle (USV) was made as an instrument that replaces the role of direct human involvement. Thus it might be useful to support the research activities such as data collection, survey and measurement in the remote and severe location with the ground control system. Many USV researches were made for oil and gas exploration, pipeline monitoring. The USV application for military operation can be found for surveillance, intelligence, search and rescue (SAR), inspection/exploration and strike missions.

In the scope of this research project, the prototype of autonomous surface vehicle was developed that will enable real time data monitoring to support bathymetry survey, especially in the coastal environment. The intact stability and the sea keeping characteristics of the developed autonomous surface vehicle were investigated in the previous study, [1]. In this paper, the study is focused on the design of the hull, propulsion system and the control system such as electronic device, sensor and data link. The SWATH hull form was selected that was expected to provide low resistance and excellent station keeping performance.

*Ahmad Fauzan Zakki, Naval Architecture Department, Diponegoro University, +622476480784, ahmadfauzanzakki@lecturer.undip.ac.id

\section{Literature Review}

Several articles which are related to the ASV design and control development can be found. An autonomous surface craft called ARTEMIS was designed by a research group in MIT for collecting the bathymetry data, [2]. ARTEMIS have two electric motors and a rudder for the propulsion system. It is equipped automatic heading and navigation control through the defined reference points that was used as the location of measurement point. Subsequently the catamaran was adopted for improving the intact stability and increasing the payload capacity.

In the other research, The DELFIM was developed as an Autonomous Underwater Vehicles (AUV), [3]. The ROAZ and ROAZ II was developed and designed for bathymetry survey, [4][5]. Furthermore the development of autonomous marine vehicle was represented by the SWORDFISH, MESSIN and SPRINGER. The SWORDFISH is equipped with the modular sensor for payload and a gateway for data communication from air to underwater environment, [6]-[7]. The catamaran hull form was used by MESSIN for hydrological mapping and oceanographic survey, [8]. The MESSIN able to operate in very shallow water and the autonomous navigation system was able to follow the defined route efficiently. In 2004, the SPRINGER was developed 
for hydrographical survey and used as a test-bed for autonomous navigation and sensor system, [9]-[10].

The study of ASV hull form development can be found in some references. In [11], the author studies the modeling of twin hull for the USV known as SESAMO for data collection in the Antarctic region. In [12], the authors develop the catamaran hull form, propulsion and control system for the ASV prototype to survey the coastal region. The integrated system for sampling and monitoring of environmental parameters has been achieved. In [1], the authors investigate the intact stability and sea keeping performance of the SWATH hull form for the ASV development to support bathymetry survey. In [13], the researchers study the performance of SWATH and catamaran hull form using CFD analysis for geological and geophysical survey.

\section{Design of ASV Hull and Drag Characteristics}

Regarding the research objective is to obtain the ASV design for bathymetry survey, this will lead to the need of a reliable vessel design which would provide a good performance of stability, station keeping and hydrodynamic behavior. According to research on ThyssenKrupp Marine Systems, [14], SWATH technology able to provide the low hydrodynamic drag, high stability and good motion performance, compared with the monohull. Therefore the SWATH hull form is adopted as an appropriate solution to carry the several electronic devices and sensors that would be used for the data scanning and recording during the bathymetry survey.

The principal dimension of the ASV was determined through the design exploration process. The process was made by involving the configuration of design parameters from the modification of the existing parent model. The proposed hull form of the SWATH-ASV which is obtained from the selected principal dimension can be seen in Fig. 1.

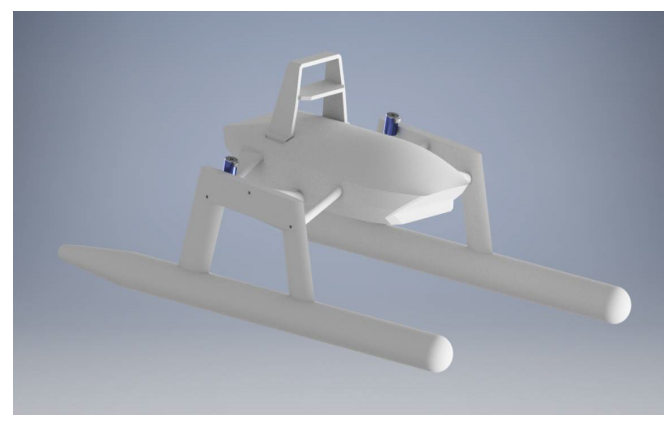

Figure 1: The hull form of the SWATH-ASV

Theoretically, the moving submerged bodies have viscous drag which is resolved into two items that is viscous pressure and frictional resistance. The viscous drag characteristic of ASV depends on the Reynolds number. In the case of surface vehicle, additional wave making resistance is provided, and it is depending on the Froude number.

The estimation of total resistance of the proposed SWATHASV was made through the CFD analysis for determining the power of propulsion system, [15]. The service speed, wetted surface area and simulation parameters were provided on the CFD analysis. The result shows that the total resistance force of the ASV is $5.55 \mathrm{~N}$. the drag coefficient is determined using parabolic equation approach, [15], see Fig.2.

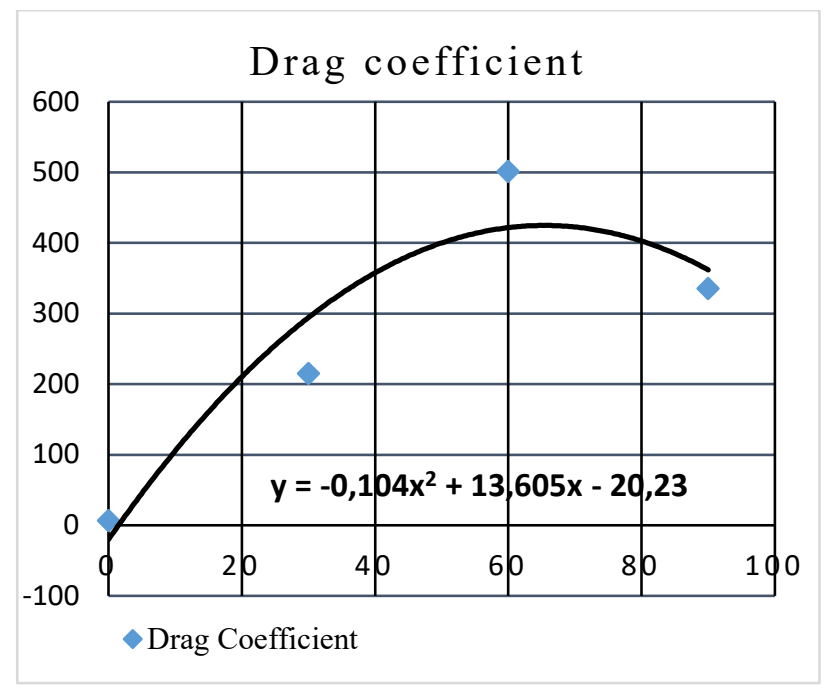

Figure 2: Drag coefficient of the SWATH-ASV, [15]

\section{Control System of the SWATH-ASV}

\subsection{Electrical System of the SWATH-ASV}

The principal electrical wiring of the SWATH-ASV is presented in the Fig. 3. Two cells LiPo batteries with an output voltage of 12.4 volts are used as the power source. Each of the batteries have a discharge rate of 30 capacity ratings which supply power for every electronic component on the SWATH-ASV, such as navigation system and data recording system.

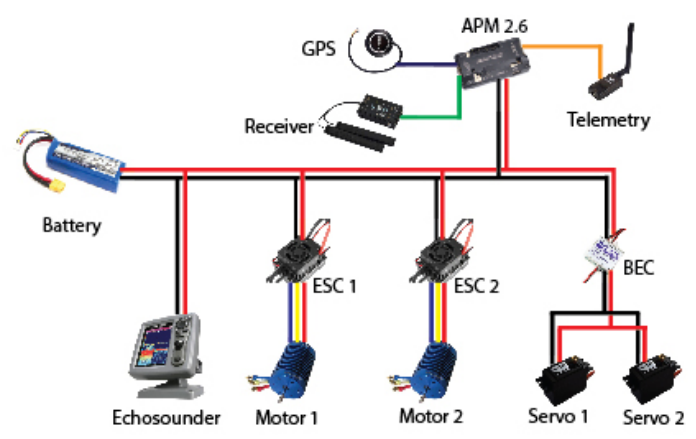

Figure 3: Wiring System

The GPS Ublox M8 is connected to the Ardupilot Mega (APM 2.6). Ardupilot Mega is an autopilot system which used inertial measurement unit (IMU) sensors. APM acts as an electronic speed controller (ESC), servo, GPS control center based on input data from mission planners and receiver. Subsequently, the data is transmitted to the ground station with the transceiver. The transmitted data are recorded using Telemetry Module $433 \mathrm{MHz}$. The direction control is made by servo motor. Otherwise the DC motor which is controlled by the ESC is adopted to control the speed of the SWATH-ASV.

When the ASV system runs in manual mode, the ship will move according to the instructions of the controller. Data will be sent to the computer in the form of ship motion direction data, GPS data and sensor data contained in the ASV. When the system runs 
in automatic mode, the ship will move automatically by using the PID control as a regulator of the ship's automatic motion while monitoring the environment around the ship. The environmental conditions are monitored and measured in the form of data stored on the device, and some of the data is sent directly by telemetry to the ground station (personal computer) in real time.

PID is a controller that functions as a ship controller to be able to move automatically or commonly called autonomous. The main function of the PID control on the Autonomous Surface Vehicle is to set the direction or heading of the ship to fit the destination, see Fig. 4. PID is a combination of several elements, namely $P$ (Proportional), I (Integral), and D (Derivatives). P, I, and D elements can quickly respond to systems to eliminate offsets. Each element has advantages to determine the appropriate value of $\mathrm{Kp}$, $\mathrm{Ki}$, and $\mathrm{Kd}$ with the manual tuning method. $\mathrm{Kp}, \mathrm{Ki}$, and $\mathrm{Kd}$ are proportional gain, integral gain and derivative gain.

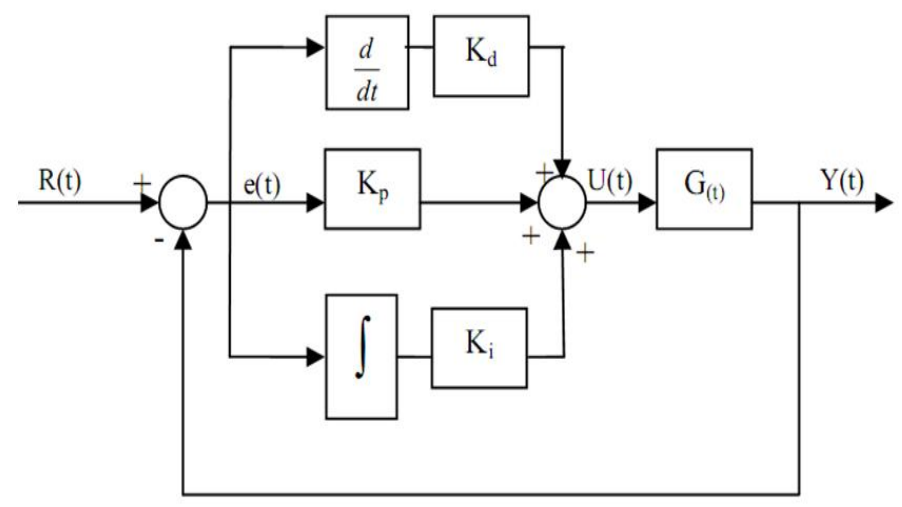

Figure 4: PID Control

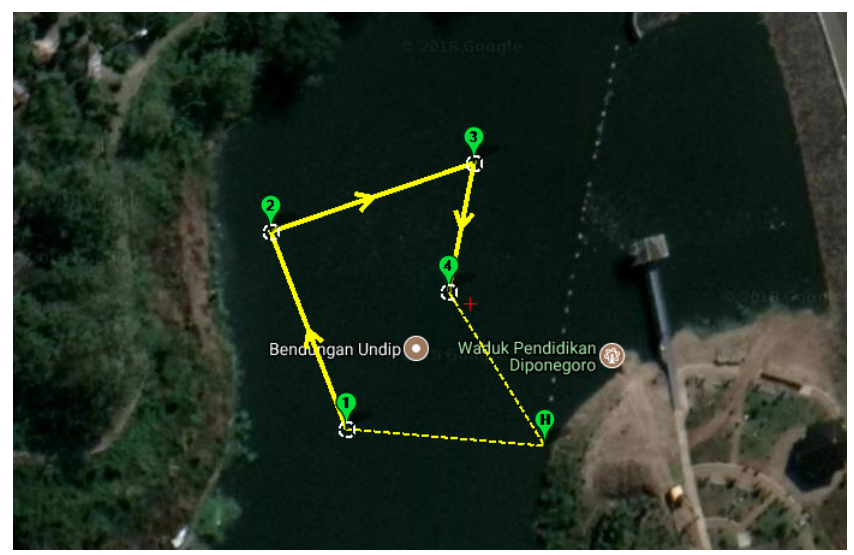

Figure 5: Waypoint Navigation System

\subsection{Navigation System of the ASV}

The Autonomous Surface Vehicle can move automatically using the GPS waypoint navigation system. Furthermore, the waypoint navigation system also able to predetermined the ASV path automatically. By importing map database from Google Map the mission planner software is adopted to define the path of the SWATH-ASV. The illustration of waypoint navigation system on the defined path of the SWATH-ASV can be seen in the Figure 5. The SWATH-ASV will run through the defined path from point to point with no obstacle along the path. Therefore the SWATH-ASV is able to follow the path relatively accurate without any difficulties.
When ASV runs automatically following a waypoint, it can be monitored using a mission planner. Some data on ASV will be sent in real time to the personal computer using the telemetry module $433 \mathrm{MHz}$. This module can transmit data like the direction of motion, ASV stability, battery capacity, current and GPS. While the echo sounder will always record the condition of the waters around the waypoint until it is finished and returns to home, see Fig. 5.

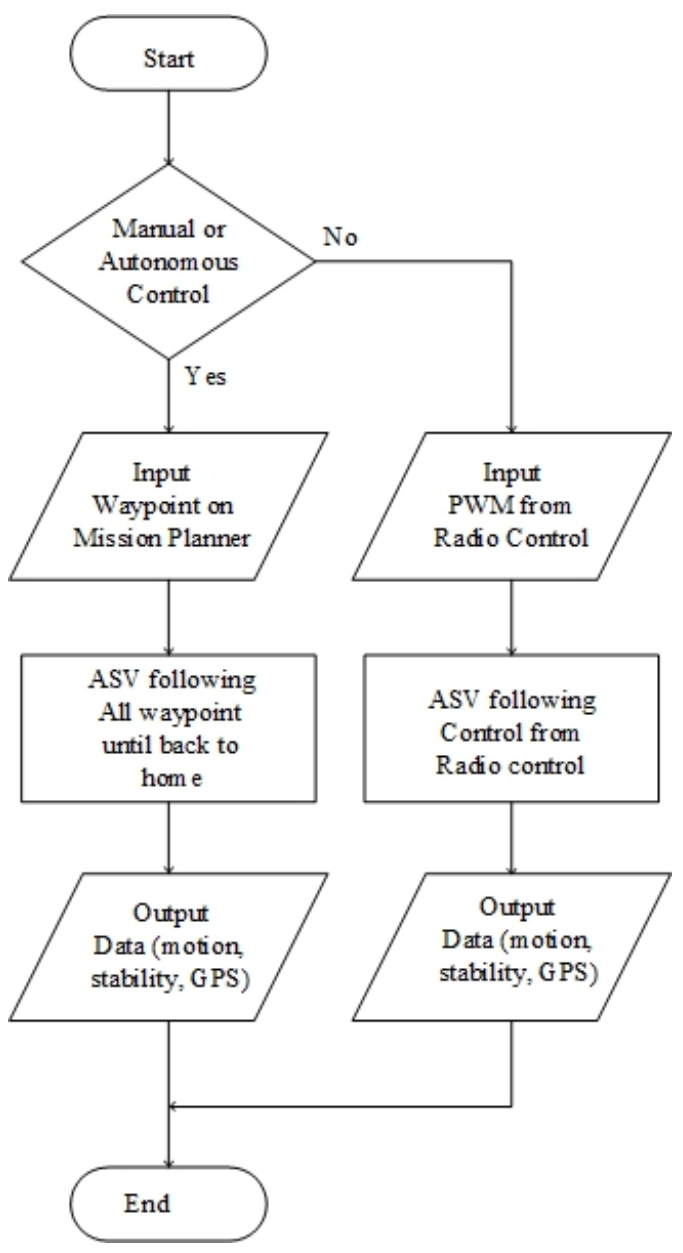

Figure 6: Flowchart System

Fig. 6 shows the flowchart of system control the SWATHASV. The RC is used to choose manual control or autonomous control. If an automatic control is chosen, the SWATH-ASV will need waypoint input from the mission planner to move to the specified waypoint, and the SWATH-ASV will automatically follow and send real time data to the personal computer. However, when the manual control is selected, the SWATH-ASV will be controlled by the navigation system, according to signals which is received from the radio/remote control. The autopilot system (Ardupilot) will arrange the motors to navigate the ASV through the defined path. The servo motor is used to control the direction and the DC motor is used to control the speed of the SWATHASV. The SWATH-ASV will always follow the received command from radio/remote control and send real time data to the personal computer.

Although the waypoint navigation system has been applied in the SWATH-ASV, however the obstacle-avoidance algorithm still not be included into this automated navigation system. The 460 
SWATH-ASV will travel blindly without any smart system that able to detect its surrounding environment. While the defined path is blocked with an obstacle, an unavoidable collision surely can be occurred. Therefore the manual system using remote control should be used for the application of the SWATH-ASV in the actual situation during bathymetry survey activities.

\section{Conclusion}

The design and control of small water-plane area twin hull autonomous surface vehicle (SWATH-ASV) was made. The SWATH hull form was adopted and realized as an alternative prototype of autonomous surface vehicle which have innovative features and suitable for supporting the bathymetry survey activities.

All of the SWATH-ASV components were designed and organized in order to be able to perform the innovative bathymetry measurement activities by considering functionality and portability aspects.

The SWATH-ASV has been developed in according to the lifting capacity requirements and to execute the bathymetry measurement mission in the coastal marine regions which have complex area logistically.

Although the autonomous control system have been implemented on the SWATH-ASV, however the remote control system is still to be adopted as a secondary control system, especially when the ASV do not follow the waypoint because of the uncontrollable external disturbance.

\section{Acknowledgment}

The authors wish to thank the reviewers for their constructive comments and suggestions helped in improving this research paper and Ministry of Research, Technology and Higher Education, Indonesia for providing the funding in carrying out this research in the scheme of PDUPT 2018.

\section{References}

[1] A. F. Zakki, A. Triwiyatno, B. Sasmito, Intact stability and seakeeping characteristics of autonomous surface vehicle (asv) using swath hullform to support bathymetry survey activities on the coastal area, MATEC Web of $\begin{array}{llll}\text { Conferences, } & \text { Vol. } & 177, \text { pp. } & 01-06,\end{array}$ https://doi.org/10.1051/matecconf/201817701001

[2] J. E. Manley, Development of the autonomous surface craft ACES, OCEANS '97 MTS/IEEE, Vol. 177, pp. 01-06, 2018. https://doi.org/10.1109/OCEANS.1997.624102

[3] Pascoal A., Oliveira P., Silvestre C., Sebastiao L., Rufino M., Barroso V., Gomes J., Ayela G., Coince P., Cardew M., Ryan A., Braithwaite H., Cardew N., Trepte J., Seube N., Champeau J., Dhaussy P., Sauce V., Moitie R., Santos R., Cardigos F., Brussieux M. and Dando P., Robotic ocean vehicles for marine science applications: the European ASIMOV project, OCEANS 2000 $\begin{array}{lllll}\text { MTS/IEEE, Vol. } & \text { 1, } & \text { pp. }\end{array}$ https://doi.org/10.1109/OCEANS.2000.881293

[4] Ferreira H., Almeida C., Martins A., Dias N., Dias A. and Silva E., Autonomous bathymetry for risk assessment with ROAZ robotic surface vehicle, OCEANS 2009 MTS/IEEE, 2009. https://doi.org/10.1109/OCEANSE.2009.5278235

[5] Ferreira H., Martins A., Dias A. and Almeida C., ROAZ autonomous surface vehicle design and implementation, Robotica, 2006.

[6] Ferreira H., Martins R., Marques E. and Pinto J., Marine Operations with the SWORDFISH Autonomous Surface Vehicle, Robotica, 2006

[7] Ferreira H., Martins R., Marques E., Pinto J., Martins A., Almeida J.M., Sousa J. and Silva E., SWORDFISH: an Autonomous Surface Vehicle for Network Centric Operations, OCEANS 2007 MTS/IEEE, 2007. https://doi.org/10.1109/OCEANSE.2007.4302467
[8] Majohr J. and Buch T., Modelling, simulation and control of an autonomous surface marine vehicle for surveying applications Measuring Dolphin MESSIN, IEE CONTROL ENGINEERING SERIES, 69 (Advanced in Unmanned Marine Vehicles, 2006, pp. 329-351). https://doi.org/10.1049/PBCE069E_ch16

[9] Naeem W., Sutton R. and Chudley J., Modelling and control of an unmanned surface vehicle for environmental monitoring, UKACC International Control Conference, 2006

[10] Naeem W., Xu T., Sutton R. and Tiano A., The design of a navigation, guidance, and control system for an unmanned surface vehicle for environmental monitoring, Proceedings of the Institution of Mechanical Engineers, Part M: Journal of Engineering for the Maritime Environment, Vol. 222(Issue 2): 67-79, 2008. https://doi.org/10.1243/14750902JEME80

[11] Caccia M., Bono R., Bruzzone G., Bruzzone G., Spirandelli E., Veruggio G., Stortini A.M. and Capodaglio G., Sampling Sea Surfaces with SESAMO, Robotics \& Automation Magazine, 2005. https://doi.org/10.1109/MRA.2005.1511873

[12] Evangelista L., Giordano L., Di Fiore V., Lengo A., a new prototype of unmanned surface vehicles to survey the coastal marine environment: design, modelling and control, Rapp. Tec. INGV, 374: 1-22, 2017. https://doi.org/10.13140/RG.2.2.19869.82409

[13] Gursel K. T., Taner M., Unsalan D., Neser G., Design of a Marine Autonomous Surface Vehicle for Geological and Geophysical Surveys, Scientific Bulletin of Naval Academy, Vol. 21: 20-36, 2018. https://doi.org/10.21279/1454-864X-18-I1-003

[14] Schellenberger G., SWATH Technology - Advanced SWATH Design Methods, ThyssenKrupp Marine Systems, 2007.

[15] A. F. Zakki, A. Triwiyatno, B. Sasmito, I. A. C. Abar, Study on Hydrodynamics Coefficient of SWATH Autonomous Surface Vehicles (ASV) Hullform for Bathymetry Survey Activities, ARPN Journal of Engineering and Applied Sciences (submitted manuscript - status in review), 2018. 